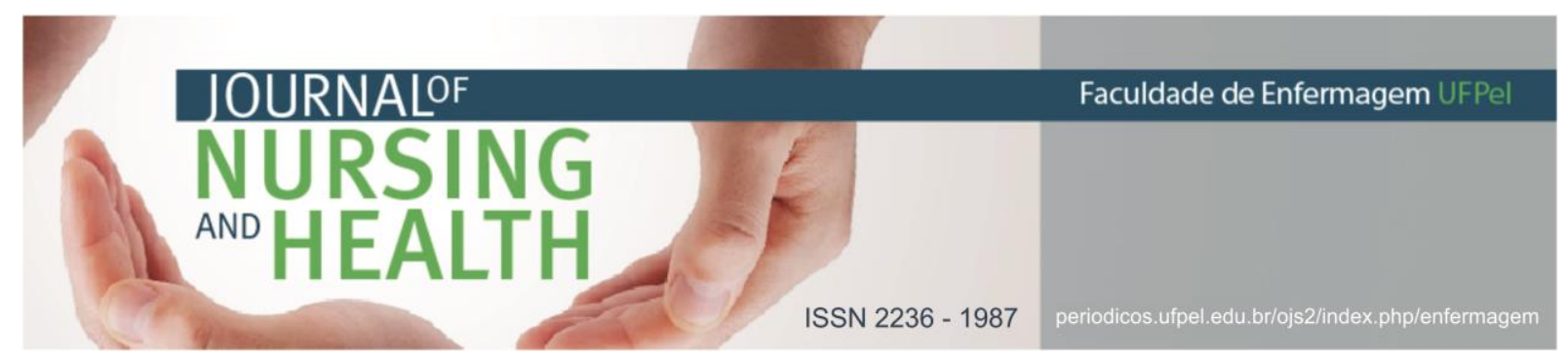

DEPOIMENTO DE EXPERT POR EXPERIÊNCIA

\title{
A experiência de ouvir vozes
}

\section{The experience of hearing voices}

\section{La experiencia de escuchar voces}

Fernandes, Henrique Campagnollo Dávila ${ }^{1}$; Argiles, Carmen Terezinha Leal ${ }^{2}$

Como citar este artigo: Fernandes HCD, Argiles CTL. A experiência de ouvir vozes. J. nurs. health. 2018;8(n.esp.):e188409

Palavras-chave: Saúde mental; Terapêuticas; Ouvidores de vozes.

\section{APRESENTAÇÃO}

Este trata-se de um relato de um ouvidor de vozes o qual integra o grupo do qual participa um dos autores do texto. Este ouvidor solicitou manter seu anonimato, mas considerou muito importante dar seu depoimento sobre este assunto, conforme explicitado a seguir:

\section{História de vida: crise e descobertas}

Começo este relato a partir da minha história de vida, antes de vivenciar a experiência de ouvir vozes, trazendo aspectos do meu contexto pessoal e de minha inserção social. Nasci na Ceilândia, Distrito Federal. Frequentei o ensino fundamental e médio com muitas dificuldades, devido à problemas cognitivos, tais como perda da atenção e concentração. Estes foram percebidos pelos professores como desinteresse e preguiça. Era muito introspectivo e calado. Assim, com 14 anos me afastei da escola, deixei os estudos e tive as primeiras experiências com o uso de álcool e drogas.

Fiz uso de substâncias, dos 14 até os 17 anos, com o objetivo de buscar alívio para o sofrimento que sentia ao ouvir vozes. As vozes se manifestaram mais intensamente, ao final da adolescência, entre 17 e 18 anos e foi muito perturbador porque comprometeram minha capacidade de interação com o mundo externo. Assim, criei um mundo próprio a partir da minha imaginação e das alucinações. Esse período foi muito marcante na minha trajetória, porque

\footnotetext{
1 Psicólogo. Mestre em Psicologia Clínica e Cultura. Universidade de Brasília (UnB). E-mail: hcdfernandes@gmail.com http://orcid.org/0000-0001-9976-8551

2 Psicóloga. Doutora em Ciências. Prefeitura Municipal de Pelotas e Prefeitura Municipal de Rio Grande. E-mail: carmen_argiles@yahoo.com.br http://orcid.org/0000-000240369553
} 


\section{NURSING \\ AND \\ OHEALTH \\ ISSN 2236 - 1987}

não tinha nenhum contato com profissionais de saúde e me encontrei sozinho com as vozes.

Acreditei que esse era o meu destino e deveria realizar o que as vozes me diziam. $O$ conteúdo das vozes era sempre negativo e era recorrente a ideia de morte. Neste período, vivi a intensa experiência de ser pai e as alucinações envolviam meu filho de modo forte e marcante. Sentia muito medo, estava confuso e perdido em relação ao meu futuro e buscava encontrar soluções para meus dilemas.

Frente às limitações, busquei ajuda médica, recebendo o diagnóstico de esquizofrenia. 0 prognóstico foi bastante negativo, prevendo empobrecimentos nas funções mentais e piora nas condições gerais. Essas informações foram recebidas com tristeza e choro, pela minha mãe e com grande desesperança por mim, que almejava uma vida com autonomia $e$ formação profissional, sonhava com o estudo do direito e a graduação em advocacia.

Neste período, devido a confusão e às dificuldades vividas, cometi um delito e me foi imposta a penalidade jurídica de "liberdade assistida". Por essa ocasião, conheci o serviço de saúde mental, ao identificarem minhas dificuldades, realizaram o encaminhamento ao Centro de Atenção Psicossocial (CAPS). Resisti inicialmente a indicação de frequentar o serviço, devido ao estigma que recai sobre esse local, temendo pelo preconceito da sociedade em relação ao sofrimento mental e a possível perda de direitos e dignidade. No entanto, neste serviço passei a valorizar e a lutar pelos direitos fundamentais de todas as pessoas à uma vida digna.

Retomando a direção de minha vida, percebi a possibilidade de cuidar de mim mesmo, para assim poder cuidar do meu filho e daqueles com quem tenho vínculos de afeto. Essa postura ativa frente às dificuldades me ajudou a recuperar a vontade de estudar e realizar meu projeto de vida, incluindo a minha condição de ouvir vozes e suas implicações.

\section{A construção de estratégias na experiência de ouvir vozes}

Iniciei minha compreensão acerca da experiência de ouvir vozes no CAPS, ao relatar minha dificuldade com as emoções. Duvidava de minha capacidade de viver o amor, a piedade, o arrependimento, entre outros sentimentos. A profissional de saúde mental me referiu então: "todo ser humano tem emoções, simplesmente pelo fato de estar vivo, você sente alguma coisa." Essa ideia me marcou profundamente, porque me possibilitou acreditar na minha autonomia para sentir. Neste momento eu seguia o que as vozes me diziam, $e$ não confiava no que eu sentia, tive então, que apreender a lidar com isso, com 


\section{NURSING \\ AND



o que ouço das vozes e com o que sinto. Passei a buscar o reconhecimento de minhas emoções e entrar em contato com elas.

Até então, as vozes eram muito negativas, ameaçavam com possíveis acontecimentos de morte, suicídio ou assassinatos, envolvendo a mim e meus familiares, sentia muito medo. Elas se fazem presentes deste modo negativo, quando não estou bem, quando vivo um desconforto, tenho um problema, quando sinto medo. Nestas ocasiões, elas se tornam mais negativas ou pejorativas, determinando o que devo fazer. Ao receber apoio e sentir-me mais seguro quanto aos meus sentimentos, desenvolvi confiança para me afirmar frente às vozes, de forma mais autônoma, isso é respeitando minhas emoções. Assim, hoje as vozes se fazem presentes de modo mais positivo, e temos uma convivência mais harmônica.

Essa mudança na relação com as vozes ocorreu com muito trabalho. Quando as vozes me direcionavam para a morte, para o suicídio, eu tentava conversar com elas como se fossem alguém que estivesse ali, dizendo o que quero e o que não quero fazer. Digo quando não posso ouvir, quando não há tempo. Mas quando posso falo com elas e hoje elas me impulsionam. No início, as vozes me indicavam a morte como saída, e atualmente me motivam a viver e realizar atividades, tais como a escrita.

Deste modo, percebi que as vozes não são um empecilho na minha vida, acredito que elas têm seu benefício, tudo é uma questão de exercitar. Estabelecemos um condicionamento em que as vozes passaram a me ajudar, $e$ percebo isso como um modo sadio de viver com as vozes, mesmo por que elas não vão embora. Entendi que as vozes são inevitáveis, não se afastarão, portanto, passei a aceitá-las como amigas, que estão presentes para me ajudar, tornando-se aliadas e companheiras.

Aprendi que muitos aspectos da nossa vida influenciam as vozes, o lugar onde vivemos, a cultura, e a ideia de que isso não é "normal". Acredito que por ouvir as vozes, tenho uma "sacada" a mais, uma responsabilidade, que é ouvir e pode exercitar isso, para vivenciar a experiência de modo saudável, evitando o sofrimento que sempre esteve relacionado as mesmas.

É necessário fazer exercícios para compreender que estas podem deixar de ser pejorativas, para se tornarem positivas. Canalizar a energia que acompanham esses fenômenos, tanto as vozes, quanto as alucinações visuais, entendendo-as como uma energia que impele para a motivação de buscar a saúde e sentir-se bem. Lutando com as armas que temos nesta trajetória.

A relação estabelecida com as vozes deixou de ser percebida como um empecilho na minha vida, e passou a ser fonte de impulso para realizar determinadas ações e reflexão acerca de quem sou e de minhas emoções. 
Tenho um meio de comunicação com elas. Às vezes, é preciso ignorar, não ouvir, mas também, dar o tempo para estabelecer com elas uma comunicação. Para mim, as vozes se configuram em uma rede de relações, na qual posso refletir, e enriquecer meu pensamento e raciocínio, a partir de posicionamento crítico e argumentativo, que posso desenvolver.

\section{Viver com as vozes: aprendizagem e perspectivas}

Com a experiência de viver, tendo as vozes como companheiras, aprendo a importância de estar livre e ser livre, para realizar escolhas e os rumos que desejo seguir. Hoje considero que tenho uma vida boa, com conforto e bemestar. Estando estabilizado e com uma boa saúde, posso trabalhar para ter êxito. Posso lutar pelos ideais em que acredito e pelas coisas que priorizo, entre estas, elenco a saúde e a estabilidade.

A capacitação e a qualificação dos profissionais, que me ajudaram no momento em que mais necessitei de apoio, foram fundamentais. O CAPS me ajudou sem acarretar restrições na minha vida, em um momento em que duvidei da minha capacidade e da minha dignidade como ser humano.

A minha vida mudou e melhorou, hoje eu vejo as vozes como possíveis companheiras, como se fossem minhas colegas de faculdade. Mas principalmente as vozes me ajudam nos questionamentos com relação à vida, aos sentimentos, a ética e sinto que elas auxiliam nas minhas reflexões.

Penso que atualmente estamos melhorando o sistema de saúde mental, que oferece oportunidades para entendermos nossas condições e experiências, sem a restrição de liberdade. Escrever, sobre nossas vozes, é algo que podemos fazer para potencializar uma vida digna a outros ouvidores de vozes, traçando uma perspectiva de futuro com menor sofrimento e maior compreensão acerca desta experiência. 